\title{
INDICATION OF ORGANIZATIONAL COLLUSION BY EXAMINING DYNAMIC MARKET INDICATORS
}

\author{
Akos Barta ${ }^{1 *}$, Mark Molnar ${ }^{2}$ \\ ${ }^{1} \mathrm{PhD}$ student, Doctoral School of Business Management, Szent István University, Hungary \\ ${ }^{2}$ Department of Macroeconomics, Institute of Economics, Faculty of Business and Social Sciences, Szent \\ István University, Hungary \\ https://doi.org/10.47833/2021.1.ECO.003
}

\author{
Keywords: \\ cartel \\ collusion \\ artificial neural networks \\ oligopolies \\ pattern recognition
}

\section{Article history:}

Received 10 Marc 2021

Revised 18 Marc 2021

Accepted 2 Apr 2021

\begin{abstract}
Natural competition provides a beneficial environment for consumers, as consumers emerge as winners of price and quality competition between organizations, as they can purchase quality products for the value of their money. For organizations, however, this competition results in a reduction of profits. Therefore organizations have an interest in distorting open market competition because they "do better." Collusion is a relatively common but hidden and illegal way of distorting market competition. It is difficult for government agencies to spot and detect such activities because they do not happen openly. Our theoretical research examines that when a collusion occurs in an oligopolistic market, certain market trends or their dynamics change relative to the dynamics of a competiive baseline situation. Thus, the fact of collusion can also be detected with high probability in terms of amplitude of changes in market share and other market indicators.
\end{abstract}

\section{Introduction}

Many markets operate in an oligopolistic structure. The peculiarity of such a market is that the few players are interested in cooperating with each other to increase the profits of the industry. These collaborations are typically hidden. Collusive cartels typically harm consumer interests and market efficiency and are therefore illegal. However, due to its secret nature, the cartel activity is difficult to detect. The study assumes that in addition to such activity, anomalies arise in market operations that can be observed. In this way, it can be shown which organizations have secret agreements in a given market, i.e. they distort the normal functioning of the market and thus harm consumers. In other words, the existence of cartels can be detected by examining market dynamism.

\section{Method}

In oligopolistic markets, due to the relatively small number of players, organizations are able to work with their competitors, thus increasing their profits. By doing so, they significantly disadvantage consumers by limiting their choices due to collusion. So they pay more for the same quality than they would in a competitive market. Cartel activity critically undermines the efficient functioning of the market. [3] The agreements are mostly secret, so the detection of illegal activity is very complicated and works on an ad hoc basis.

The first major scientific analysis can be attributed to Becker (1968) [2], in which he examines the economics of crime. According to him, the player's decision is based on the difference between the expected benefit of the illegal move and the expected value of the penalty (probability weighted penalty), while the authorities try to minimize the distortion of the normal functioning of the market

\footnotetext{
* Corresponding author. Tel.: +36 309056396 E-mail address: mail@bartaakos.com
} 
and the damage caused. According to this theory, the authorities are therefore obliged to maximize the penalty that can be imposed, thus reducing cartel activity.

Market competition provides consumers with products and services under the best possible conditions:

- Efficiency and innovation reduce prices.

- Constant pressure from competitors is a constant motivation.

A cartel is a group of independent and similar companies that agree to fix prices, set production quotas or share customers and markets:

- Reduces the incentive to develop new or better products and services and provide them at competitive prices.

- In some markets, some customers (consumers or other companies) pay more for lower quality. [13]

At present, cartel activities are most exposed to the European Commission's leniency policy, as self-reporting drastically reduces the penalty for illegal activity. The possibility of self-declaration increases prosperity. [7]

The European Commission's so-called leniency policy encourages companies to provide inside information on the existence of cartels. The first to do so from the cartel is exempted from the fine. The leniency policy has so far been a successful tool in ending cartels.

Agreements are almost always illegal if the participants agree to:

- price fixing,

- production restrictions,

- market or consumer segmentation,

- fixing resale prices (between producer and distributors).

However, the agreement may be authorized if:

- has favorable rather than adverse effects,

- not bound by competitors,

- jointly concluded only by undertakings with a small market share,

- necessary for the development of products or services, the development of new products or the development of new, more appropriate methods of delivering products to consumers.

Despite the work of the European Commission, cartel activity has not decreased in the last few years, even considering the declining trend in the level of fines imposed between 2016 and 2018. In $2019,69 \%$ more penalties were imposed compared to 2018. [1]

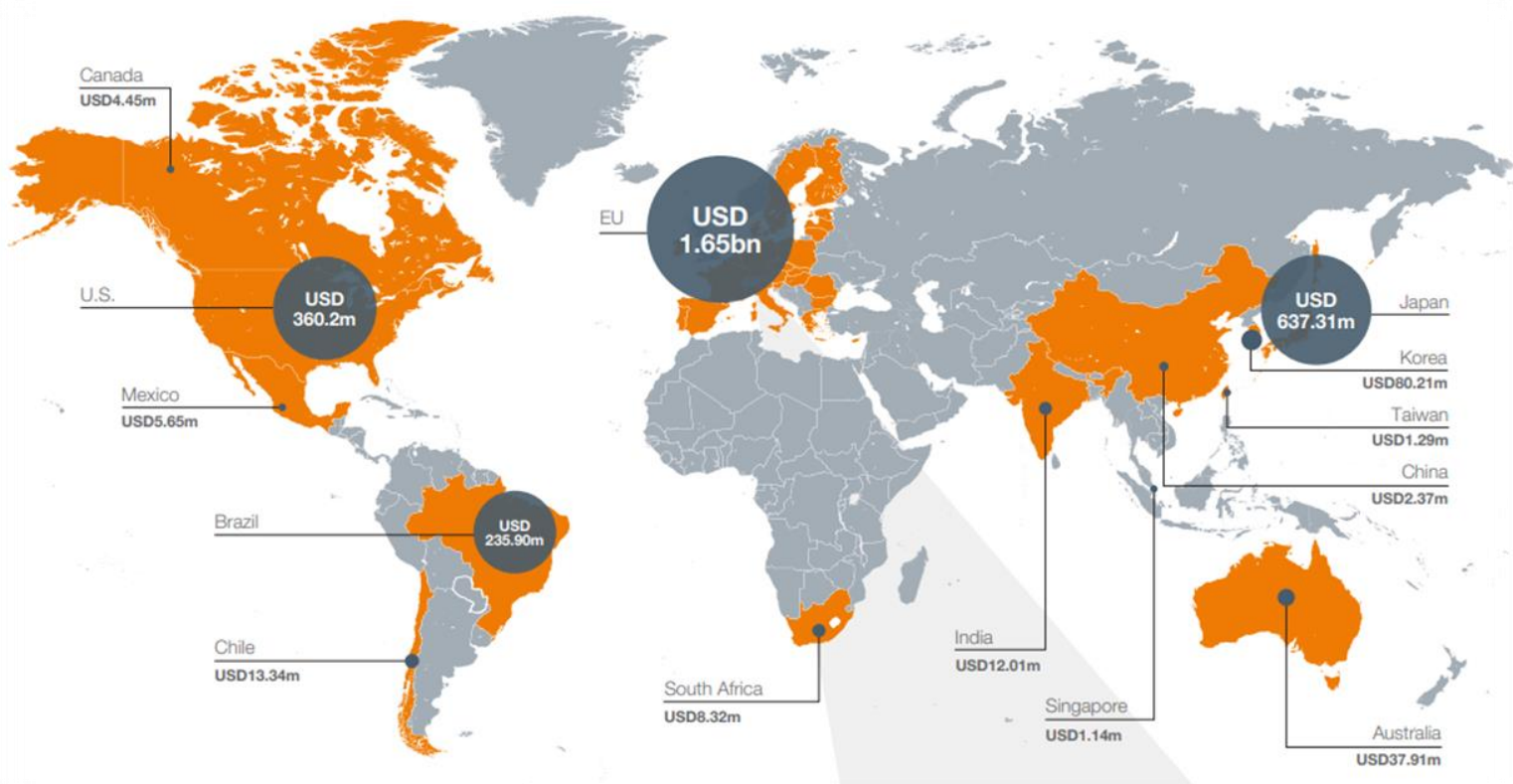

Figure 1. Global Cartel Fine 2019 (Source: Allen \& Overy (2020)) 
Due to the leniency policy, it is in the interest of the parties to breach the cartel. [8] Cartels are thus able to disintegrate even in the absence of government intervention, so the long-term maintenance of cartel activity pays off only in markets that are difficult to enter, so cartel activity in particular needs to be examined. A competitive market provides higher output than a cartel, so the collective profit of the cartel is induced by a decrease in output or an increase in price. It is worthwhile for companies to engage in cartel activities if they can raise prices on a lasting basis through collusion, so that they can operate effectively in the long run. [4]

At the same time, the price increase will also make the market attractive to new entrants. In this case, the cartel is unable to maintain the high price, so their cooperation becomes unstable. In addition, an additional risk factor for cartel activity is the increase in demand for substitute products from other industries due to rising prices. Substitute products also have an impact on the functioning of the cartel market. [5]

We currently know a lot about the cartels that have already come to light, but very little about the cartels that are still in place. The purpose of the organizations involved in the cartel is to increase profits, which can be achieved by increasing revenues or by reducing costs. Four factors can keep costs low: the small number of companies involved; highly concentrated market; homogenity of products; the existence of trade associations. The easier it is for the other participants in the cartel to notice that the agreement has been breached, the easier it will be to comply with the agreement. [6]

A cartel is the worst, most dangerous form of competition infringement. Because they are secret, that is, hidden from customers, regulation or detection (as well as defense) is critical.

Detecting cartels is difficult (almost impossible) because cooperation is hidden from the market, agreements are secret.

Numerous studies suggest that cartel activity in oligopolistic markets can be detected by changes in exogenous costs, since there is a significant difference in cartel activity compared to normal competitive market dynamism.

- Incorporate and analyze the rate of response to changes in exogenous production costs motion differential equation.

- We examine the change in market share (its dynamism) by observing and studying the reactions to the actions of other players.

A common problem with the approaches is that there is no exact quantified threshold (or band) that could be a clear boundary line to indicate the operation of a cartel.

Numerous studies suggest that cartel activity in oligopolistic markets can be detected by changes in exogenous costs. [9] In other words, there is a significant difference in the case of cartel activity compared to the normal competitive market dynamism. It is possible to examine responses to cost shocks. [10] We can also examine the market share and its change by measuring the gradients of change in the market share of the company. [11]

In real life, the participants in each cartel try to hide the existence of their cooperation. Without direct evidence, it can be very difficult to identify the operation of cartels.

\section{Discussion}

Based on previous models [14] we assume a finite number of players and homogeneous goods in oligopolistic markets. The linear demand function:

$$
Q_{d}=A-b P, \quad A, b>0
$$

For simplicity, we use the classic Cournot model:

$$
f\left(\sum_{l=1}^{n} x_{l}\right)=b-A \sum_{l=1}^{n} x_{l}
$$


and the cost functions are: $c_{k}\left(x_{k}\right)=c_{k} x_{k}+d_{k}$. The variables $b, A, c_{k}$ are positive constants. The probability variable $d_{k}$ follows a white noise process: where $d_{t}=d_{t-1}+\varepsilon_{t}$ ahol $\varepsilon^{\sim N}(0,1)$. Costs may increase or decrease randomly and with equal probability.

Suppose that the alignment parameter $u$ influences the share of costs in the output decision of the organization, i.e., how quickly and to what extent companies respond to changes in their costs, e.g. with a price increase. Then the $k$. the company's profit can be given as follows:

$$
\phi_{k}\left(x_{1}, \ldots, x_{n}\right)=x_{k}\left(b-A \sum_{l=1}^{n} x_{e}\right)-\left(c_{k} x_{k} u+d_{k}\right) \text {, }
$$

where $u$ is the (control) variable that affects unit production costs. Other types of controls can be examined in a similar way (Okuguchi - Szidarovszky, 1999). When developing the relevant dynamic models, we first assume that the time scale is discrete. In each period, each company maximizes its expected profit:

$$
x_{k}\left(b-A x_{k}-A \sum_{l \neq k}^{n} x_{l}(t-1)\right)-\left(c_{k} x_{k} u+d_{k}\right)
$$

where we assume that every firm expects all rivals to produce the same as in the previous period. These types of expectations are called static in the economic literature. We also assume that each company selects output that maximizes profits for each period. Assuming it is positive, simple differentiation shows

$$
x_{k}=-\frac{1}{2} \sum_{l \neq k} x_{l}(t-1)+\frac{b-c_{k} u(t-1)}{2 A}, \quad k=1 . . n
$$

These equations can be rewritten into the standard system form by introducing the following new state variables:

$$
z_{k}(t)=x_{k}(t)-\frac{b}{(N+1) A}
$$

thus:

$$
z_{k}(t)=-\frac{1}{2} \sum_{l \neq k} z_{k}(t-1)-\frac{c_{k}}{2 A} u(t-1)
$$

It is a linear system with system coefficients

$$
\left(\begin{array}{cccc}
0 & -\frac{1}{2} & \cdots & -\frac{1}{2} \\
-\frac{1}{2} & 0 & \cdots & -\frac{1}{2} \\
\vdots & \vdots & & \vdots \\
-\frac{1}{2} & -\frac{1}{2} & \cdots & 0
\end{array}\right) \text { and } \underline{b}\left(\begin{array}{c}
-\frac{c_{1}}{2 A} \\
-\frac{c_{2}}{2 A} \\
\vdots \\
-\frac{c_{n}}{2 A}
\end{array}\right)
$$

If different firms are managed differently, the cost expression $\left(c_{k} x_{k} u_{k}+d_{k}\right)$ in the equation is modified so that 


$$
z_{k}(t)=-\frac{1}{2} \sum_{l \neq k} z_{l}(t-1)-\frac{c_{k}}{2 A} u_{k}(t-1)
$$

will be shaped with the following system coefficients

$$
\underline{A}=\left(\begin{array}{cccc}
0 & -\frac{1}{2} & \cdots & -\frac{1}{2} \\
-\frac{1}{2} & 0 & \cdots & -\frac{1}{2} \\
\vdots & \vdots & & \vdots \\
-\frac{1}{2} & -\frac{1}{2} & \cdots & 0
\end{array}\right) \text { and } \underline{B}=\operatorname{diag}\left(-\frac{c_{1}}{2 A},-\frac{c_{2}}{2 A}, \ldots,-\frac{c_{n}}{2 A}\right)
$$

Suppose we have a continuous model and that in each period, individual firms adjust their production in proportion to marginal profit. If companies are managed equally, the shape of the dynamic model will be as follows:

$$
\dot{x}_{k}(t)=S_{k}\left(-2 A x_{k}(t)-A \sum_{l \neq k} x_{l}(t)+b-c_{k} u(t)\right)
$$

where $S_{k}>0$ is $k$. company adaptation speed. Here

$$
\underline{A}=\underline{S}\left(\begin{array}{cccc}
-2 A & -A & \cdots & -A \\
-A & -2 A & \cdots & -A \\
\vdots & \vdots & & \vdots \\
-A & -A & \cdots & -2 A
\end{array}\right) \text { and } \underline{b}=\underline{S}\left(\begin{array}{c}
-c \\
-c_{2} \\
\vdots \\
-c_{n}
\end{array}\right)
$$

If firms react differently, the cost term in the equation is $c_{k}{ }^{*} u$ instead of $c_{k}{ }^{*} u_{k}$.

\section{Conclusions}

We presented a market anomaly, carteling, which is typically an oligopolistic market phenomenon. This anomaly is based on collusion between market players and causes a significant decline in consumer welfare. We proposed a new approach to identify such typically hidden activities. Further research would focus on modeling and data collection. In the absence of data, market simulations are able to fill the gap and provide modeling data.

The significance of the proposed method is that it would allow the detection and identification of suspected cartel cases on the basis of available market data. In order to determine a certain degree of deviation from the competitive operation of the examined market, it is expedient to use neural networks, which would be based on the market dynamisms of the already proven cartel activities. It is likely that the method, even if it would work, would not provide sufficient evidence in legal matters, but would be a very useful tool for consumers and law enforcement agencies to deal with notifications. 


\section{References}

[1] Allen \& Overy (2020) Global cartel enforcement report 2020 February

[2] Becker, G. S. (1968) Crime and Punishment: An Economic Approach. Journal of Political Economy, 76(2) pp. 169217. doi: 10.1007/978-1-349-62853-7_2

[3] Bloch, F. (1996) Sequential Formation of Coalitions in Games with Externalities and Fixed Payoff Division, Games and Economic Behavior, 14(1), pp. 90-123 doi: 10.1006/game.1996.0043

[4] Carlton, D. W. - Perloff, J. M. (2016) Modern Industrial Organization, $4^{\text {th }}$ ed, Pearson Education Limited, Harlow ISBN: 9781292087856

[5] Connor, J. M. (2005) Collusion and price dispersion, Applied and Economics Letters, 12(6) pp. 335-338. doi: 10.22004/ag.econ.28639

[6] Fonseca, M. A. - Normann, H. (2012) - Explicit vs. tacit collusion-The impact of communication in oligopoly experiments, European Economic Review, 56(8) pp. 1759-1772. doi: 10.1016/j.euroecorev.2012.09.002

[7] Kaplow, L. - Shavell, S. (1994) Optimal Law Enforcement with Self-Reporting of Behavior. Journal of Political Economy, 102(3) pp. 583-606. doi: 10.1086/261947

[8] Katsoulacos, Y. - Motchenkova, E. - Ulph, D. (2015) Penalizing cartels: The case for basing penalties on price overcharge, International Journal of Industrial Organization, 42. pp. 70-80. doi: 10.1016/j.ijindorg.2015.07.007

[9] Levenstein, M. C. - Suslow, V. Y. (2006) What Determines Cartel Success?, Journal of Economic Literature 44(1) pp. 43-95. doi: 10.1257/002205106776162681

[10] Molnár, S. - Szidarovszky, F. (1994) A diszkrét idejü oligopólium játékok stabilitásáról, SZIGMA 25(3) pp. $103-113$.

[11] Molnár, S. (1992) Bertrand, Cournot and Mixed Oligopolies, Keio Economic Studies 29(1) pp. 1-7.

[12] Okoguchi, K. - Szidarovszky, F. (1999) The Theory of Oligoply with Multi-Product Firms, Springer-Verlag, Berlin /Heidelberg/New York ISBN 978-3-642-60169-9

[13] Severova, L. - Bendl, S. (2013) Cartels and their behaviour on food markets, Agricultural Economics - Zmdeleska Ekonomika, 59(2) pp. 81-89. doi: 10.17221/52/2012-AGRICECON

[14] Szidarovszky, F. - Molnár, S. - Molnár, M. (2014) Extended oligopoly models and their asymptotical behavior, Mechanical Engineering Letters: R and D: Research And Development 11. pp. 44-56. ISSN 2060-3789 